\title{
Aplikasi Pencarian Informasi Kondisi Jalan Dan Jarak Wisata Menggunakan Metode Fuzzy Dan Algoritma Dijkstra
}

\author{
Sumiati ${ }^{1}$, Arief Nurrohman $^{2}$ \\ ${ }^{1,2}$ Program Studi Teknik Informatika Fakultas Teknologi Informasi Universitas Serang Raya \\ Jln. Raya Cilegon Serang KM. 5 - Taman Drangong Kota Serang \\ ${ }^{1}$ sumiati82@yahoo.com \\ 2 ariefnurrohman79@gmail.com,
}

\begin{abstract}
Abstrak - Kabupaten Serang memiliki cukup banyak tempat atau objek-objek wisata, Hal ini membuat kabupaten serang menjadi salah satu destinasi wisata yang wajib dikunjungi bagi masyarakat dan wisatawan Namun kabupaten serang memiliki penataan sistem jalur wisata yang cukup banyak dan cukup kompleks. Kebutuhan informasi jalur menuju daerah wisata sangatlah penting bagi masyarakat atau wisatawan. Di era teknologi yang serba maju seperti sekarang ini, dan smartphone menjadi salah satu pilihan untuk mencari informasi karena di nilai lebih praktis.Aplikasi pencarian informasi kondisi jalan dan jarak terdekat perlu dibuat demi memudahkan akses informasi mengenai jalur dan tempat wisata. Aplikasi pencarian informasi ini dirancang berbasis Android, metode yang digunakan adalah metode fuzzy dan juga algoritma dijkstra. Metode fuzzy digunakan untuk memberikan sebuah output berupa nilai dengan menggunakan variabel yaitu variabel jarak dan variabel lebar jalan. yang nantinya nilai tersebut akan dijadikan bobot didalam algoritma djikstra untuk pencarian jarak terdekatnya. Menggunakan model UML (Unified Modelling Language) dengan Software Android Studio serta menggunakan SQLite. Hasil dari pembuatan aplikasi ini diharapkan wisatawan dapat lebih mudah untuk melakukan proses pencarian informasi kondisi jalan dan jarak terdekat wisata di Kabupaten Serang.
\end{abstract}

Kata Kunci : Android, Kabupaten Serang, Pariwisata, Rute alternative

\section{PENDAHULUAN}

Kabupaten Serang memiliki cukup banyak tempat atau objek-objek wisata, hal ini membuat kabupaten Serang menjadi salah satu destinasi wisata yang wajib dikunjungi bagi masyarakat dan wisatawan. Namun Kabupaten Serang memiliki penataan sistem jalur wisata yang cukup banyak dan cukup kompleks. Hal ini membuat wisatawan kesulitan untuk mengakses jalan untuk menuju tempat wisata. Karena wisatawan akan dipusingkan dengan cukup banyaknya jalan dan rumitnya lalu lintas di Kabupaten Serang. Ditambah lagi belum tersedianya aplikasi untuk mencari informasi kondisi jalan dan jarak terdekat pada daerah wisata. Kebutuhan informasi jalur menuju daerah wisata sangatlah penting bagi masyarakat atau wisatawan. Di era teknologi yang serba maju seperti sekarang ini, dan smartphone menjadi salah satu pilihan untuk mencari informasi karena dinilai lebih praktis. Oleh karena itu, untuk mengatasi masalah diatas tentu perlu dibuatkan sebuah aplikasi yang dapat memudahkan wisatawan untuk mendapatkan informasi mengenai kondisi jalan dan jarak terdekat untuk menuju tempat wisata. Maka dibuatlah sebuah aplikasi yaitu "Aplikasi pencarian informasi kondisi jalan dan jarak wisata menggunakan metode fuzzy dan algoritma dijkstra." Sistem operasi android digunakan sebagai basis dalam pembuatan aplikasi ini dan metode yang digunakan adalah metode fuzzy dan juga algoritma dijkstra. Metode fuzzy digunakan untuk memberikan sebuah output berupa nilai dengan menggunakan variabel yaitu variabel jarak dan variabel lebar jalan. yang nantinya nilai tersebut akan dijadikan bobot didalam algoritma dijkstra.

Diharapakan hasil dari pembuatan aplikasi ini nantinya, wisatawan dapat lebih mudah untuk melakukan proses pencarian informasi mengenai kondisi jalan dan jarak terdekat di Kabupaten Serang. Wisatawan hanya perlu memasukan lokasi awal, dan lokasi tujuan, maka wisatawan akan langsung mendapatkan informasi kondisi jalan dan jarak terdekat pada lokasi wisata.

\section{METODOLOGI PENELITIAN}

Model pengembangan dalam pembuatan aplikasi ini adalah dengan metode waterfall 


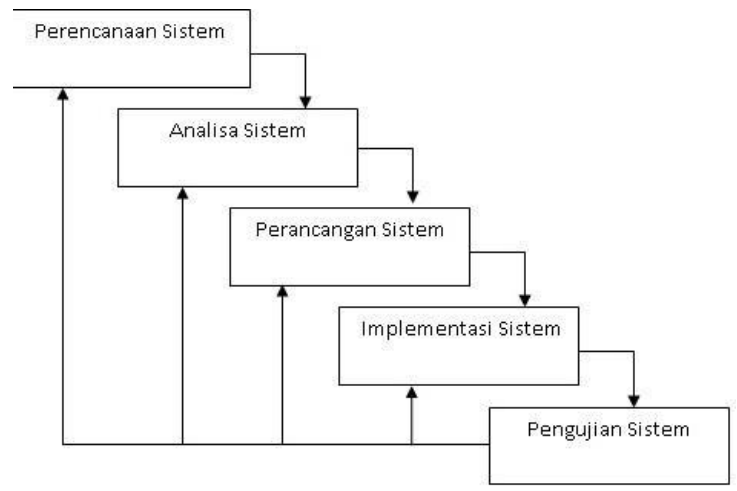

Gambar 1. Model Waterfall

Langkah - langkah dari waterfall yaitu meliputi : pengumpulan data, Analisa, esain Sistem, Pengkodean, Pengujian, Operasi dan pemeliharaan.

B. Metodologi Perhitungan

1. Proses perhitungan logika fuzzy Fuzzyfikasi

Menentukan variabel semesta pembicaraan pada proses analisis data. Terdapat 2 jenis input yang akan dimasukan kedalam sistem yaitu :

Tabel 1. Variabel Semesta pembicaraan

\begin{tabular}{|c|l|l|l|}
\hline Fungsi & \multicolumn{1}{|c|}{$\begin{array}{c}\text { Nama } \\
\text { Variabel }\end{array}$} & $\begin{array}{c}\text { Semesta } \\
\text { Pembicaraan }\end{array}$ & \multicolumn{1}{|c|}{ Keterangan } \\
\hline \multirow{2}{*}{ Input } & Jarak & {$[2,1-21]$} & $\begin{array}{l}\text { Nilai rata }- \\
\text { rata Jarak }\end{array}$ \\
\cline { 2 - 4 } & $\begin{array}{l}\text { Lebar } \\
\text { Jalan }\end{array}$ & {$[2,5-7]$} & $\begin{array}{l}\text { Nilai rata }- \\
\text { rata kondisi jalan }\end{array}$ \\
\hline Output & $\begin{array}{l}\text { Kondisi } \\
\text { Jalan }\end{array}$ & {$[2-10]$} & $\begin{array}{l}\text { Nilai rata - } \\
\text { rata kondisi jalan }\end{array}$ \\
\hline
\end{tabular}

Tabel 2. Himpunan fuzzy

\begin{tabular}{|c|c|c|c|c|}
\hline Fungsi & Variabel & $\begin{array}{c}\text { Himpunan } \\
\text { Fuzzy }\end{array}$ & $\begin{array}{c}\text { Semesta } \\
\text { Pembicaraan }\end{array}$ & Domain \\
\hline & \multirow{3}{*}{ Jarak } & Dekat & \multirow{3}{*}[2,1-21]{} & {$[2,1-5]$} \\
\hline & & Sedang & & {$[2,1-21]$} \\
\hline & & Jauh & & {$[7-21]$} \\
\hline & \multirow{3}{*}{$\begin{array}{l}\text { Lebar } \\
\text { Jalan }\end{array}$} & Sempit & \multirow{3}{*}[2,5-7]{} & $2,5-4,5$ \\
\hline & & Sedang & & $2,5-7$ \\
\hline & & Lebar & & $5-7$ \\
\hline \multirow{3}{*}{ Output } & \multirow{3}{*}{$\begin{array}{l}\text { Kondisi } \\
\text { Jalan }\end{array}$} & Rusak & \multirow{3}{*}{ [2-10] } & {$[2-4]$} \\
\hline & & Sedang & & {$[2-10]$} \\
\hline & & Baik & & [6-10] \\
\hline
\end{tabular}

a. Variabel Jarak

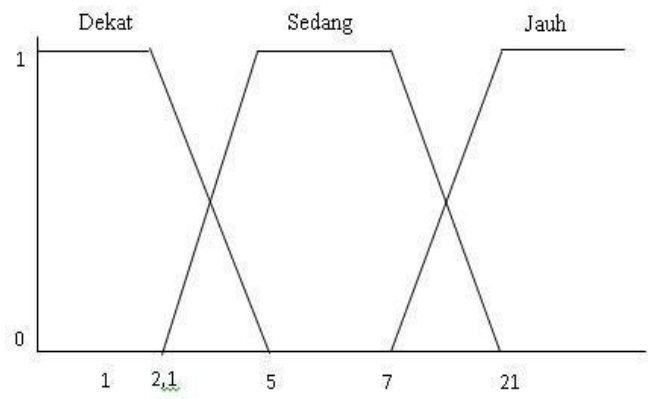

Gambar 2 Grafik Variabel Jarak

$\mu$ Dekat $[10]=0$

$\mu$ Sedang $[10]=(21-10) /(21-7)$

$$
=11 / 14
$$$$
=0,78
$$

$\mu$ Jauh [10] $=(10-7) /(21-7)$

$$
=3 / 14
$$

$$
=0,21
$$

b. Variabel Kondisi Jalan

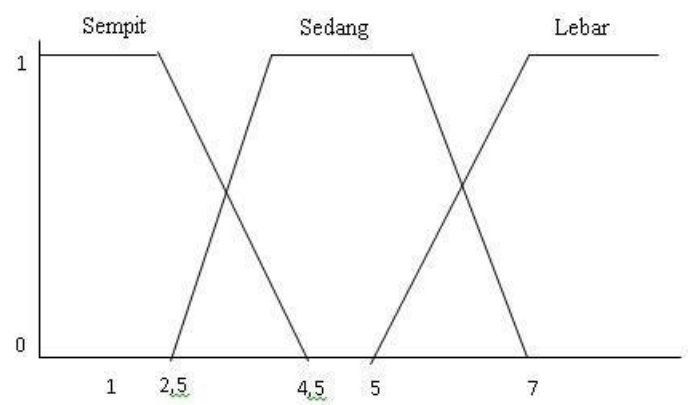

Gambar 3. Grafik Variabel Kondisi

Jalan $\mu$ Sempit $[3]=(4,5-3) /(4,5-2,5)$

$$
\begin{aligned}
& =1,5 / 2 \\
& =0,75
\end{aligned}
$$

$\mu$ Sedang [3] $=(3-2,5) /(4,5-2,5)$

$$
\begin{aligned}
& =0,5 / 2 \\
& =0,25
\end{aligned}
$$

$\mu$ Lebar [3] $=0$

Proses Pembentukan Aturan Rule

1. IF Jarak Jauh AND Lebar Jalan

Sempit THEN ..... (1)

(1) IF Jarak Jauh AND Lebar Jalan

Sedang THEN ..... (2)

(2). IF Jarak Jauh AND Lebar Jalan

Lebar THEN ..... (3)

(3.) IF Jarak Sedang AND Lebar Jalan

Sempit THEN

(4.) IF Jarak Sedang AND Lebar Jalan

Sedang THEN ....

(5.) IF Jarak Sedang AND Lebar Jalan

Lebar THEN ..... (6)

(6.) IF Jarak Dekat AND Lebar Jalan

Sempit THEN ..... (7)

(7.) IF Jarak Dekat AND Lebar Jalan

Sedang THEN 
(8.) IF Jarak Dekat AND Lebar Jalan Lebar THEN ..... (9)

Pembentukan Max - Min

Dengan Menggunakan metode inferensi mamdani, diperoleh proses inferensi dengan menggunakan aturan Conjuction $(\wedge)$ terdapat Dua aturan baru diatas untuk mengambil nilai derajat keanggotaan minimum dari nilai linguistik yang ada. Berikut ini adalah aturan baru yang diperoleh :

1. IF Jarak Sedang $(0,78)$ AND Lebar Jalan Sempit $(0,75)$

THEN Kondisi Jalan Rusak $(0,75)$

2. IF Jarak Sedang $(0,78)$ AND Lebar Jalan Sedang $(0,25)$

THEN Kondisi Jalan Sedang $(0,25)$

3. IF Jarak Dekat (0) AND Lebar Jalan Sempit $(0,75)$ THEN

Kondisi Jalan Sedang (0)

4. IF Jarak Dekat (0) AND Lebar Jalan Sedang $(0,25)$ THEN

Kondisi Jalan Baik (0)

Berdasarkan perhitungan diatas, diperoleh 4 nilai linguistik dengan nilai derajat keanggotaan yang berbeda, Yakni :

1. Kondisi Jalan Rusak $(0,75)$

2. Kondisi Jalan Sedang $(0,25)$

3. Kondisi Jalan Sedang (0)

4. Kondisi Jalan Baik (0)

Langkah selanjutnya adalah menggunakan aturan disjunction $(\wedge)$ untuk menentukan nilai derajat keanggotaan maksimum dari nilai - nilai linguistik yang dihubungkan

1. Kondisi Jalan Rusak (0,75). Dihasilkan Kondisi Jalan Rusak $(0,75)$

2. Kondisi Jalan Sedang (0,25). v Kondisi Jalan Sedang

(0) Dihasilkan Kondisi Jalan Sedang $(0,25)$

3. Kondisi Jalan Baik (0) Dihasilkan Kondisi Jalan Baik (0). Defuzifikasi

$\sum$

$$
=\frac{(2+3) * 0,75)+(4+5,5+6) * 0,25)}{0,75+0,75+0,25+0,25+0,25}
$$

$$
=\frac{3,75+3,875}{2,252,25}=\underline{7,625}=3,38
$$

2. Proses perhitungan Algoritma Dijkstra

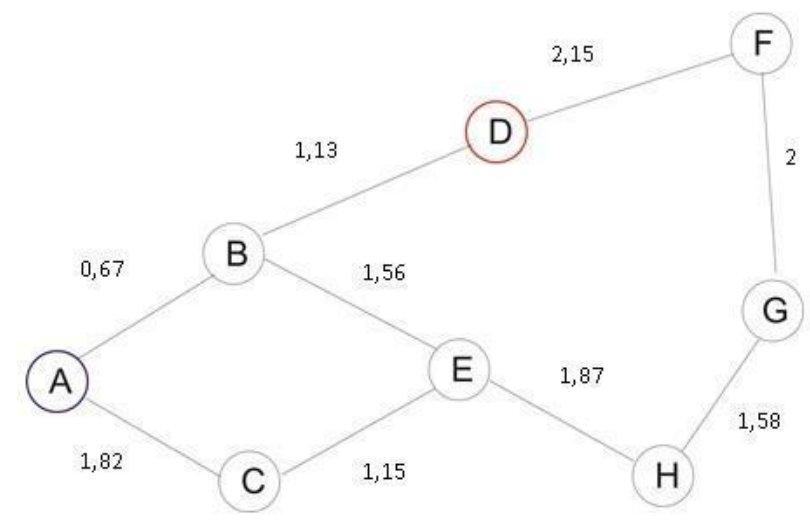

Gambar 4. Gambar Pemodelan Graph

Dari Graph Diatas diperoleh hasil dari perhitungan menggunakan metode algoritmadijkstra

\begin{tabular}{|c|c|c|c|}
\hline Dari & Menuju & $\mathrm{Ru}$ & Jarak/Panjang \\
\hline A & B & A & 0, \\
\hline A & C & A & 1, \\
\hline A & D & A-B-D & 1 \\
\hline A & E & A-B-E & 2, \\
\hline A & F & A-B-D-F & 3, \\
\hline A & G & A-B-E-H-G & 5, \\
\hline A & H & A-B-E-H & 4 \\
\hline
\end{tabular}

\section{HASIL DAN PEMBAHASAN}

A. Tampilan Sistem

Pada aplikasi pencarian informasi kondisi jalan dan jarak pada wisata ini terdapat beberapa halaman yang dapat diakses oleh pengguna. Tampilan sistem dapat dilihat pada gambar - gambar sebagai berikut :

1. halaman Utama

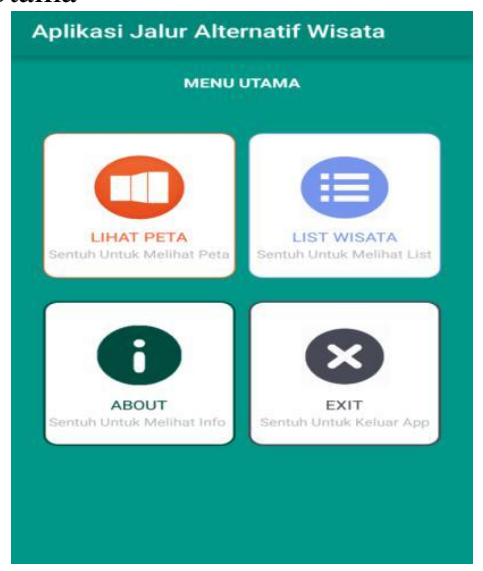

Gambar 5. Halaman Utama

Halaman utama atau menu utama adalah halaman yang pertama kali dilohat oleh user ketika membuka aplikasi ini

2. Halaman Cari Rute

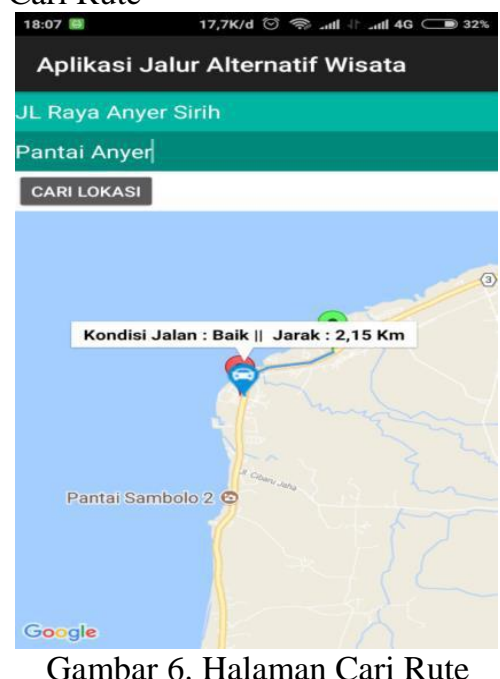


Halaman ini dapat dilihat ketika user memilih menu cari rute pada menu utama. Halaman cari rute merupakan halaman dimana user dapat mencari informasi tentang kondisi jalan serta jarak terdekat menuju tempat wisata

3. Halaman List Wisata

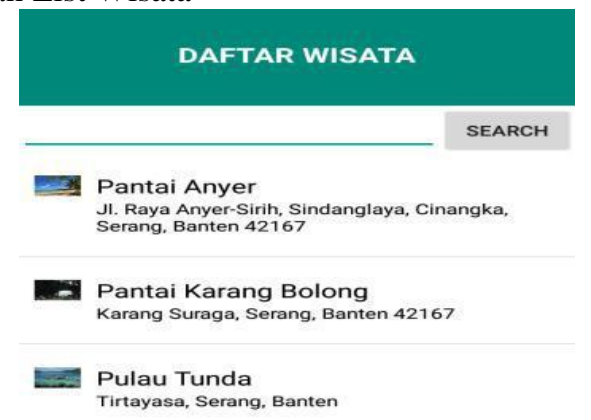

Gambar 7. Halaman List Wisata

Halaman ini berisi tentang daftar -daftar wisata yang terdapat pada sistem

4. Halaman Detail Wisata
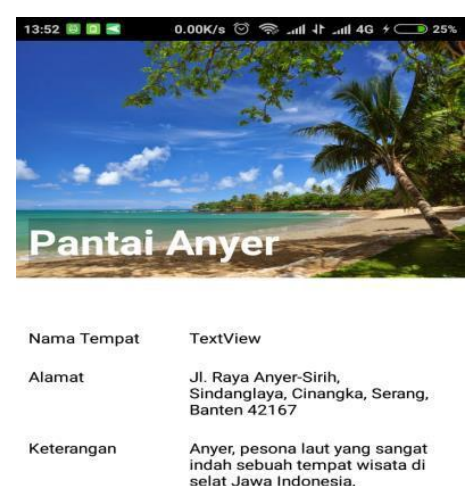

Gambar 8. Halaman Detail Wisata

Halaman ini berisi informasi tentang wisata yang dipilih pada halaman List Wisata. Informasi tersebut adalah Nama Wisata, Alamat dan Keterangan Wisata.

5. Halaman About

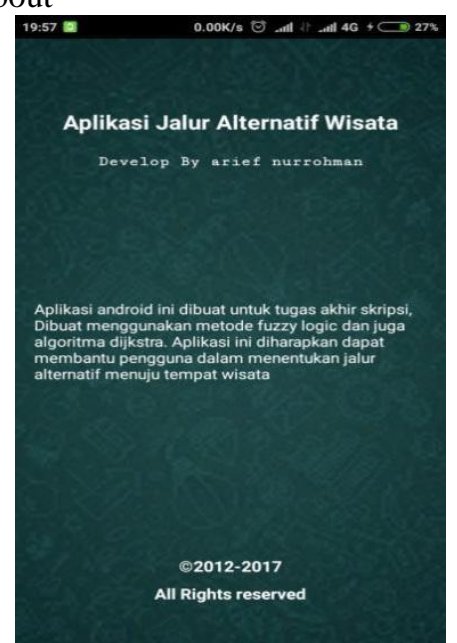

Gambar 9. Halaman About
Menu about berisi tentang informasi yang ada pada aplikasi berbasis android ini.

\section{KESIMPULAN}

Berdasarkan uraian pada bab-bab sebelumnya, maka dapat ditarik kesimpulan bahwa:

1. Penelitian ini berhasil membuat sebuah aplikasi yang mampu mencari informasi kondisi jalan dan jarak terdekat pada wisata Pantai Anyer dengan memvisualisasikan kedalam peta.

2. Dengan adanya aplikasi ini dapat membantu masyarakat dalam mencari informasi tentang kondisi jalan dan juga jarak terdekat pada daerah wisata Pantai Anyer.

Berdasarkan kesimpulan diatas, maka penulis mencoba memberikan saran. Adapun saran yang penulis kemukakan adalah sebagai berikut:

1. Tidak menutup kemungkinan akan diadakannya pembaharuan secara berkala

terhadap aplikasi ini atau melengkapi kelemahankelemahan, agar aplikasi ini selalu berjalan optimal dan sejalan dengan perkembangan data dan teknologi.

2. Tempat wisata dan pencarian rute alternatif pada aplikasi ini hanya pada daerah Pantai Anyer dan sekitarnya. Kedepannya dapat dikembangkan menjadi lebih banyak daerah wisata.

3. Proses penentuan lokasi awal dan trackingdapatdikembangkan menggunakan sistem Global Positioning System (GPS).

4. Diharapkan aplikasi ini dapat bermanfaat dan digunakan dengan baik oleh masyarakat.

\section{REFERENSI}

[1] Android, (2015). Android Studio [Online].Tersedia : https://developer.android.com/ (Diakses pada tanggal 05 April 2017).

[2] Arifianto, Sofyan, (2012). Sistem aplikasi penentuan rute terpendek padajaringan multi moda transportasi umum menggunakan algoritma djikstr [Online]. Tersedia http://eprints.undip.ac.id/36054/ [30Maret 2017].

[3] A. S., Rosa dan Shalahuddin, M. (2013).Rekayasa Perangkat Lunak Terstruktur Dan Berorientasi Objek. Bandung : Informatika [Online]. Tersedia: https://scholar.google.co.id [31 Maret 2017].

[4] Bogas Priatmoko, S. (2014). Algoritma Djikstra untuk pencarian jalur terdekatdan rekomendasi objek pariwisata di pulau Bali [Online]. Tersedia http://eprints.dinus.ac.id/13345/[30 Maret 2017].

[5] Henderi, (2008). Analysis and design System with Unified Modeling Language (UML) [Online]. Tersedia:https://www.academia.edu/25449466/Object_O riented_Modelling_With_Unified_Modeling_Language_ Uml [30 Maret 2017].

[6] Kusumadewi, Sri.(2003). Artificial Intelligence (Teknikdan Aplikasinya). Yogyakarta: Graha Ilmu. 
[7] Lovindha, Olga, (2015). Sistem pendukung keputusan rekomendasipemilihan dan pemesanan tempat wisata menggunakan metode fuzzy sugeno [Online].Tersedia:http://eprints.unisbank.ac.id/1480/1/0 8.01.53.0091.pdf [01 April 2017].

[8] Wikipedia. (2016). Kabupaten Serang [Online] tersedia http: ://id.wikipedia.org/wiki/Kabupan Serang [20 april 2017]

[9] Rribanten. (2012). Peta Wisata Kota Serang Provinsi Banten [Online]. Tersedia : https://rribanten.wordpress.com/tag/ peta-wisata/ [20 April 2017].

[10] Rahayu, Riana, (2011). Sistem pemandu wisata Berorientasi pada Adaptable Budget Dengan pemetaan jaringan transportasi umum (Studi Kasus : Surabaya) [Onilne]. Tersedia: http://repo.pens.ac.id/1098/ [02 April2017].
[11] Scribd. (2016). Dasar Teori Logika Fuzzy [Online].Tersedia:https://www.scribd.com/doc/307274 526/Dasar-Teori-Logika-Fuzzy [04April 2017].

[12] Suryo Saputro, S (2013). Sistem aplikasi penentuanrute terpendek pada jaringanmulti moda transportasi umum menggunakan algoritma djikstra.[Online].Tersedia:http://eprints.undip.ac.id/360 54/ [02April 2017].

[13] UBAYA, (2014). Android : Sistem Operasi Smartphone.[Online].Tersedia:http://www.ubaya.ac.id/ 2014/content/articles_detail/7/Android--SistemOperasi-pada-Smartphone.html [05April 2017].

[14] Whitten L, Jeffery, et al, (2007) System Analysis and Design Methods $7^{\text {th }}$ Edition, Mcgraw Hill, New York. [Online].Tersedia https://www.academia.edu/8787830/

[15]Whitten_and_Bentley_2007_System_Analysis_and_Desi gn_Methods_-_7th_Edition.[10 April 2017]. 